Nigerian Journal of Environmental Sciences and Technology (NIJEST)

www.nijest.com

ISSN (Print): 2734-259X ｜ＩSSN (electronic): 2734-2603

Vol 5, No. 2 October 2021, pp 456 - 467

\title{
Spatio-Temporal Evaluation of Urban Growth of Zuru Metropolis, Nigeria
}

\author{
Maleeks Y. A. ${ }^{1}{ }^{*}$, Aliyu A. O. ${ }^{2}$, Bala A. ${ }^{2}$, Isiaka A. U. ${ }^{3}$ and Atta K. Z. ${ }^{2}$ \\ ${ }^{1}$ Agricultural and Bio-Environmental Engineering Technology, College of Agriculture Zuru, Kebbi State, \\ Nigeria \\ ${ }^{2}$ Department of Geomatics, Ahmadu Bello University - Zaria, Kaduna State, Nigeria \\ ${ }^{3}$ Department of Surveying and Geinformatics, Waziri Umaru, Federal Polytechnics, Birnin Kebbi, Nigeria \\ Corresponding Author: *zmaleeks@gmail.com
}

https://doi.org/10.36263/nijest.2021.02.0293

\begin{abstract}
The pattern of development in a city is mostly governed by urban dynamics, with population increase being the primary driving force. Built-up cover is the most important predictor of urban expansion. Zuru metropolis in Kebbi State has witnessed remarkable developmental activities caused by human influences such as buildings, road constructions, and population growth for over decades. Urban growth was ascertained for a period of 30 years through the analysis of Landsat imagery of 1988, 1998, 2008 and 2018. The datasets were classified into five (5) land covers, namely, built-up, water body, rocky surface, vegetation, and others. Quantitative assessment of the urban growth was ascertained by computing post-classification LC dynamics and Land Consumption Rate/Land Absorption Coefficient (LCR/LAC). The results showed that the built-up cover (urban area) conspicuously increased with area of $693.35 \mathrm{ha}, 728.74 \mathrm{ha}, 5210.5 \mathrm{ha}$ and 6845.75 ha respectively for the period of study (1988 - 2018). The increment in built-up area was indicative of population growth from 1988 to 2018. The study revealed that between 1988 to 2018 showed that built-up increased by $11.78 \%$, while rocky surface and water body have shrunk by $16.44 \%$ and $0.02 \%$ respectively, which can be attributed to anthropogenic activities in which rocky surface and waterbody have been transformed into built-up cover. It further revealed that the urban area experienced crowdedness in the years 2008 and 2018 respectively due to high LCR values of $2.71 \%$ compared to LCR values of $0.0714 \%$ and $0.0558 \%$ in 1988 and 1998. Land transformation into urban area and spread of the population to the outskirts of the study area was prominent between 1998 and 2008 due to high LAC value of 0.0998. The study concluded that there was transformation of rocky surface and waterbody into urban area, which was caused by population growth, human and agricultural activities in Zuru metropolis.
\end{abstract}

Keywords: Built-up, Change detection, Land Absorption Coefficient, Land Coefficient Ratio, Urban growth

\subsection{Introduction}

Conspicuous transformation of the lithosphere, due to both natural and manmade influences, which is connected to man's drive to expand his shelter, has been evident in the $21^{\text {st }}$ century (Foley et al., 2005). Urban growth is related to landscape transformation (Forman, 1995). Although these two processes are completely similar, urban growth defines growth from non-urban to an urban area, whereas landscape transformation defines types of fragmentation, such as reductions of non-urban areas (Viana et al., 2019). Urban growth is a spatial and demographic process and refers to the increased importance of towns and cities as a concentration of population within a particular economy and society (Bhatta, 2010). Therefore, the motif of LULC reflects the arrangement or spatial scattering of the built environment (Viana et al., 2019). 
Outlying growth is distinguished by a transition from non-urban to urban land use that happens away from existing urban districts. In isolated growth, one or more non-urban regions are urbanized at a distance from existing urban centers. This sort of growth is typical of a new house or a similar construction, surrounded by little or no urban space (Wilson et al., 2003). The indicators of urban growth are land use and land cover (LULC). The LULC serves as a tool for quantitatively measuring urban growth overtime. Land use as defined by Ololade et al. (2008) is the manner in which human beings employ the land and its resources. Land covers are the regular contributors of the physical condition of the ground surface (Jeevalakshmi et al., 2016). Land cover refers to features of land surface, which may be natural, semi-natural, managed, or manmade (Bhatta, 2010).

Changes in land cover, according to many academics, have become a key issue in the broader discussion of global warming; and that change originates from human-induced influences on the environment and their implications for climate change (Lambin et al., 2001; Woldeamlak, 2002; Ginblett, 2006). Detection of LC changes is the process of identifying differences in the state of an area or region by analyzing images acquired on different dates (Singh, 1989; Ololade et al., 2008). Various cities in Nigeria have seen a significant shift in land cover, which has been mostly affected by humans. This is due to urban migration as a result of population increase, growing poverty, and a high percentage of unemployment. Abbas and Iguisi (2008) reported that the growth of agricultural activities and urbanization are the predominant and proximate causes of land use and land cover change activities in Nigeria. Similarly, this is not an exception in Zuru and its surroundings, which have large-scale agricultural (Bello et al., 2014).

In recent years, remotely sensed (RS) technology has been used in the monitoring of LULC, with encouraging results. The RS technology has evolved into an essential tool for stakeholders to use in evaluating and anticipating LULC as it occurs throughout time (Aliyu et al., 2020). Previous studies have used remotely sensed datasets to assess land cover over time in various developing countries across the world (Rimal et al., 2020). Some of the studies addressed: analysis of LULC changes (Mmom and Fred-Nwagu, 2013; Bello et al., 2014; Mishra et al., 2014); analysis of LC changes (Bakr et al., 2010; Abiodun et al., 2011; Fichera et al., 2012); change detection of urban sprawl (Oyinloye, 2010; Tamilenthi and Baskaran, 2011; Viana et al., 2019); monitoring and forecasting of spatiotemporal LULC using CA Markov (Yikalo, 2009; Sundara Kumar et al., 2015; Aliyu et al., 2020).

In an earlier study of the land use-land cover changes of Zuru and its environment by Bello et al. (2014), a period of twenty-two (22) years was analyzed using Landsat 5 (TM) imageries of 1986, 1999 and Landsat 7 (ETM+) imagery of 2008 in ILWIS software. It is more than a decade between the year 2008, when the aforementioned study was done, and the year 2018. Therefore, Zuru local government area has witnessed remarkable expansion, growth and developmental activities such as building, road construction, deforestation and many other anthropogenic activities just like many other local government headquarters in Nigeria. This has further resulted in increased land consumption and a modification and alterations in the status of her land cover over time. It is therefore, necessary for a study such as this to be carried out if Zuru was to avoid the associated problems of a growing and expanding urban area like many others in the world.

It is against this fact that this study aimed at carrying out spatio-temporal evaluation and forecasting of urban growth of Zuru Metropolis, Nigeria to locate specific growth of built-up areas and other land covers. The aim was achieved through these objectives, namely: 1) derive land cover maps of the area for 1988, 1998, 2008 and 2018); and 2) quantify land cover change metrics from the generated maps. This current study covered the whole of Zuru LGA, which is 52ha as opposed to $36.36 \mathrm{~km}^{2}$ that was studied by Bello et al. (2014). This study analyzed the LC of Zuru for four (4) epochs at 10 years interval, over a period 30 years. Therefore, this study improved upon the work of Bello et al. (2014). However, the major limitation encountered was the acquisition of Landsat 7 with much cloud as it could introduce mixed colors into the image maps. The findings of the study can be applied for planning and development of Zuru metropolis. 


\subsection{Methodology}

\subsection{Study area description}

Zuru local government area (LGA) is located in the South Eastern region of Kebbi State Nigeria with a total land mass of 52.153 .92 ha. It lies between longitude $4^{\circ} 27^{\prime} 0^{\prime \prime} \mathrm{E}$ to longitude $6^{\circ} 00^{\prime} 00^{\prime} \mathrm{E}$ of the central meridian and latitude $10^{\circ} 50^{\prime} 24^{\prime \prime} \mathrm{N}$ to Latitude $11^{\circ} 50^{\prime} 24^{\prime \prime} \mathrm{N}$ of the equator and. Zuru is bounded in the West by Gwandu and Yauri while in the East it shares boarder with Kuyanbana. It has a population of about 165,335 as at 2006 (NPC, 2006).

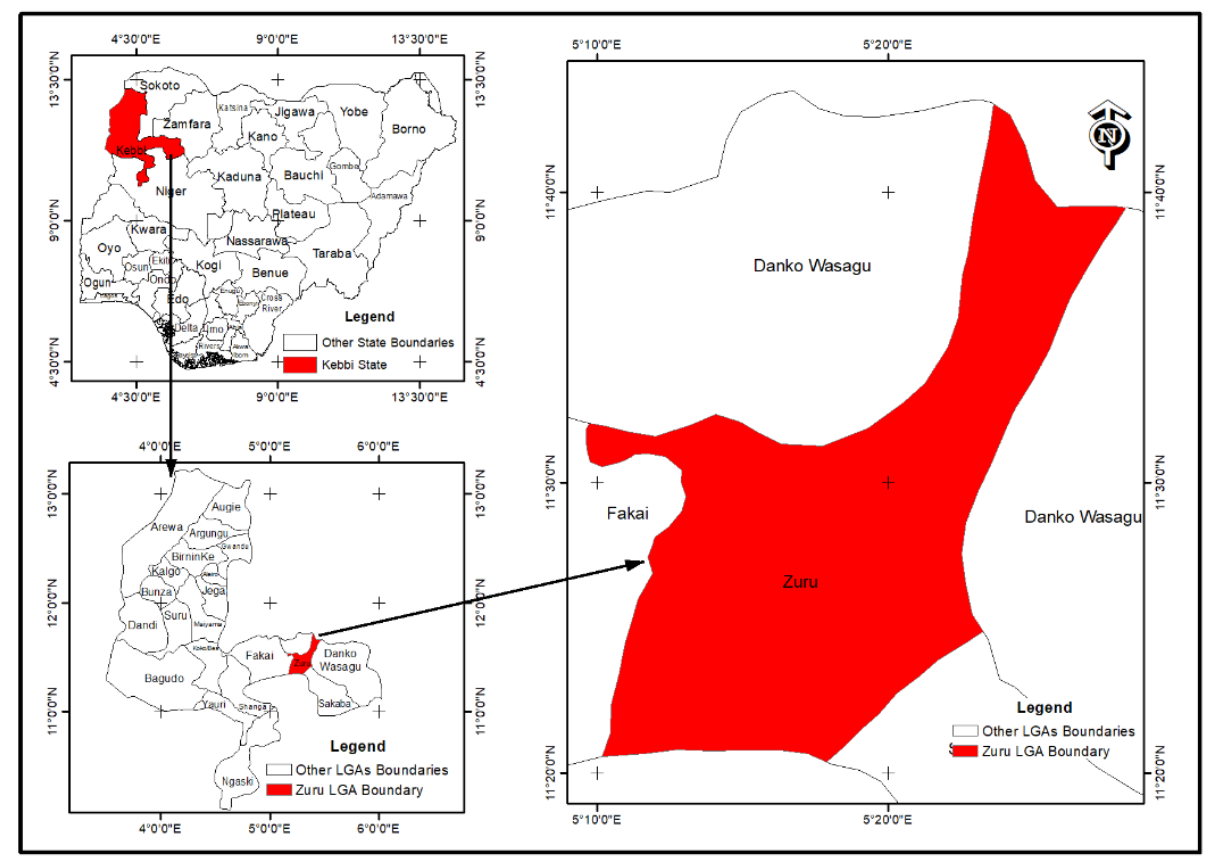

Figure 1: Inset map of the study area

\subsection{Methods}

The techniques used for the study, which cut across data collection, processing and analysis of the land covers is shown in Figure 1.

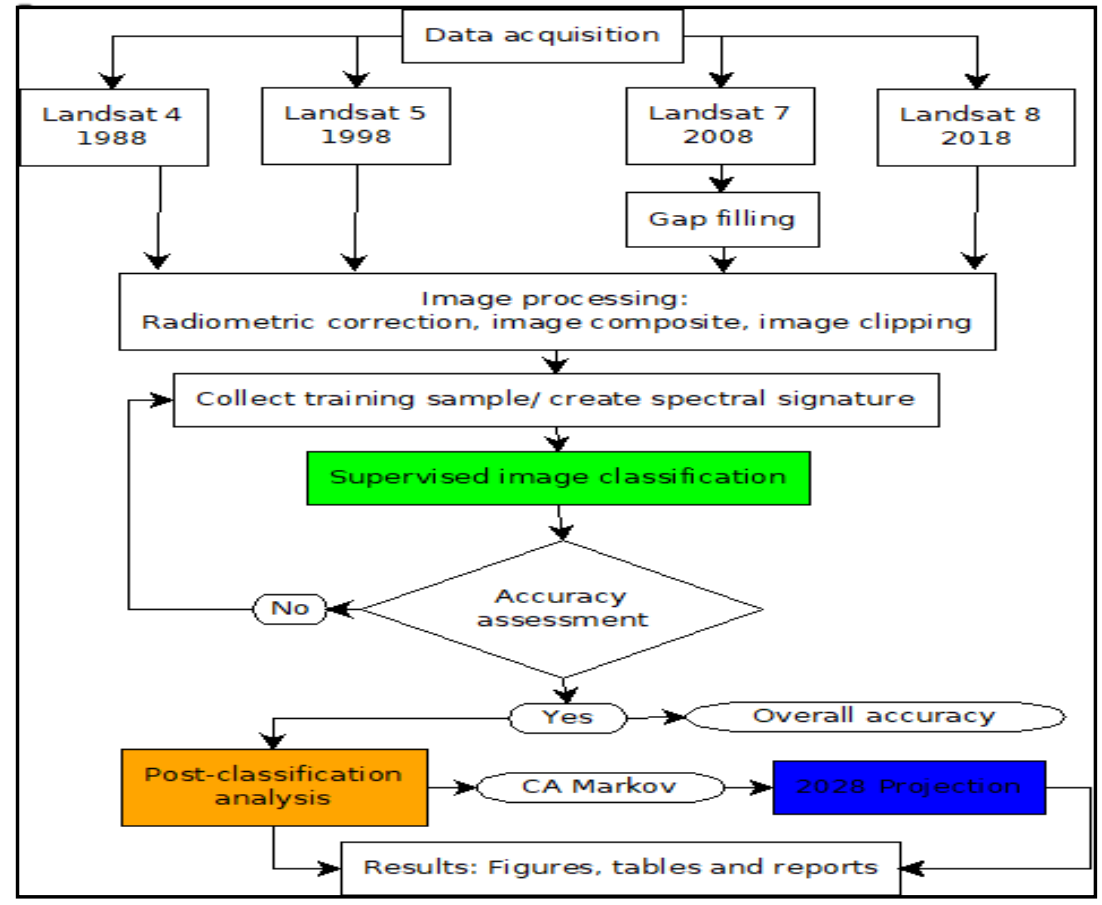

Figure 2: Workflow diagram of the study 


\subsection{Datasets and sources}

Near anniversary (November and January) multispectral optical remotely sensed datasets were acquired having path/row of 190/52. The images were acquired in the dry season to avoid dense vegetation. The images were registered to Projected Coordinate System WGS 84, UTM Zone-31N. The images were cloud-free except for the Landsat 8 . The details of the various datasets and their sources are shown in Table 1 .

Table 1: Datasets and their Characteristics

\begin{tabular}{|c|c|c|c|c|c|}
\hline $\mathrm{S} / \mathrm{N}$ & Data Type & Date & $\begin{array}{l}\text { Resolution } \\
\text { /Scale }\end{array}$ & Source & Purpose \\
\hline 1. & Landsat 4 TM & $29 / 01 / 1988$ & $30 \mathrm{~m}$ & http://www.glovis.usgs.gov & Land cover classification \\
\hline 2. & Landsat 5 TM & $16 / 11 / 1998$ & $30 \mathrm{~m}$ & http://www.glovis.usgs.gov & Land cover classification \\
\hline 3. & Landsat 7 ETM+ & $13 / 01 / 2008$ & $30 \mathrm{~m}$ & http://www.glovis.usgs.gov & Land cover classification \\
\hline 4. & Landsat 8 OLI & $07 / 01 / 2018$ & $30 \mathrm{~m}$ & http://www.glovis.usgs.gov & Land cover classification \\
\hline 5. & Google Earth Pro & $02 / 01 / 2018$ & $1 \mathrm{~m}$ & http://www.googleearth.com & Visual interpretation \\
\hline 6. & Administrative map & $05 / 08 / 2018$ & ---- & http://www.gadm.org & Extraction of study area \\
\hline
\end{tabular}

\subsection{Data processing}

Scan line correction of Landsat 7 ETM+

The scan gaps in the Landsat 7 images were filled appropriately using the histogram matching method in ENVI v5.1.

\section{Radiometric correction}

Radiometric correction was applied to the Landsat images. The level of the correction was from digital number (raw) to at-sensor spectral radiance. This was to compensate for the difference in acquisition time and date of the sensors. Conversion to surface reflectance was not carried out since surface materials were not generated for this study such as indices. The algorithms for the radiometric correction are shown in Equations 1 and 2.

1. Conversion of DN to radiance (for TM and ETM+)

$$
\left.L_{\lambda}=\frac{L_{M A X \lambda}-L_{\text {MIN } \lambda}}{Q_{\text {calmax }}-Q_{\text {calmin }}}\left(Q_{\text {CAL }}-Q_{\text {CALMIN }}\right)+L_{\text {MIN } \lambda}\right)
$$

2. Conversion of DN to Radiance (for OLI and TIRS)

$$
L_{\lambda}=M_{L} \times Q_{c a l}+A_{L}
$$

where:

$L_{\lambda} \quad$ Spectral radiance at the sensor's aperture

$Q_{C A L} \quad$ Quantized calibrated pixel value (DN)

$Q_{\text {calmin }}$ Maximum quantized pixel value (corresponding to $\mathrm{L}_{\mathrm{MAX} \lambda}$ ) in $\mathrm{DN}=255$

$L_{M I N \lambda} \quad$ Spectral radiance that is scaled to $Q_{\text {calmax }}$ (W. m-1. ster-1. $\mu \mathrm{m}-1$ )

$L_{M A X \lambda} \quad$ Spectral radiance that is scale to $Q_{\text {calmin }}$ (W. m-1. ster-1. $\mu \mathrm{m}-1$ )

$M_{L} \quad$ Band-specific multiplicative rescaling factor from the metadata (RADIANCE_MULT_BAND_x, where $x$ is the band number).

$A_{L} \quad$ Band-specific additive rescaling factor from the metadata (RADIANCE_MULT_BAND_x, where $x$ is the band number) (LSDS, 2019). This operation was carried out in ENVI v5.1.

\section{Image composite and clipping}

For the Landsat TM and ETM+ images, band 1, 2, 3, 4, 5 and 7. Also, band 2, 3, 4, 5, 6, and 7 were stacked for Landsat 8 for color renditions. Then clipping was carried out using the boundary shapefile in ArcMap v10.5.

\subsection{Data analysis}

\section{Pixel-based image classification}


Here, varying numbers of training samples were collected from the images and converted into spectral signatures. Then, supervised image classification was carried out on the images and the Maximum Likelihood Classifier (MLC) was used as a parametric decision rule. It assumes (Ongsomwang, 2007) that the probabilities are equal for all classes and that the input bands have normal distribution. However, the drawback of the MLC is that when low-spatial resolution satellite image is used, and especially, if mixel (mixed pixel) exist in the image, there would be a possibility of overlapping of probability distribution in the feature space. Thus, a high classification accuracy cannot be always expected for a low-resolution satellite image (Susaki and Shibasaki, 2000). The Landsat images were classified into five (5) classes, namely: built-up, waterbody, rocky surface, vegetated land and others (all other land use and land cover not included in any of the classes described). They were based on the Anderson LULC classification system (Anderson et al., 1976).

\section{Accuracy assessment}

The accuracy assessment was computed for the classified images to evaluate the degree of misclassification among LCs due to omission and commission. A total of 50 sample points were generated for each image in a stratified random sampling manner to generate error matrices. The idea here was to have ten (10) sample points for each class since there were five (5) land cover classes identified for the study.

\section{Change detection analysis}

Change detection analysis was performed for the five LC classes at intervals: 1988-1998, 1998-2008, 2008-2018 and 1988-2018 respectively. Four (4) LC change maps were outputted to display the change of the classified images. The change detection statistics was computed using the Module for Land Use Simulation Change Evaluation (MOLUSCE) plug-in in qGIS v10.1 software. The change analysis was both quantitative and graphical. It computed the land cover area, change in area and area percentage.

\section{Land absorption coefficient/land consumption rate}

LCR is a measure of compactness that reflects a city's progressive spatial growth. When the value of LCR is high, it indicates crowdedness and if the value is low, it indicates free spaces. Whereas LAC is a measure of how much additional urban land is consumed for each unit growth in population. It shows how fresh land is being exploited for development and how the population is spreading to the periphery or sprawling (Laxmikant et al., 2012).

It requires land area of the city (built-up) in hectares and the corresponding population size, for the respective years of interest (Aliyu et al., 2020). The estimated built-up area was obtained from the classified maps (Figure 4). The calculations were based on the assumption that land consumption grows with population growth, resulting in increased urban expansion (Laxmikant et al., 2012). The mathematical expressions for the LAC and LCR are shown in Equations 3 and 4 (Yeates and Garner, 1976):

$$
\begin{aligned}
L(\text { ha }) & =\frac{\text { CityExtensionHectares }(A)}{\text { Population }(P)} \\
L(h a) & =\frac{\text { Extent for the recent year }\left(A_{2}\right)-\text { Extent for the early year }\left(A_{1}\right)}{\text { Population for the recent year }\left(P_{2}\right)-\text { Population for the early year }\left(P_{1}\right)}
\end{aligned}
$$

The population size was estimated (Parker, 2002) using the projected population expression (Equation 5) with the establishment census data of 2006 and the 3.0\% growth rate for the study area.

$$
\operatorname{Pop}_{(\text {projected })}=\operatorname{Pop}_{(\text {known })} \times\left(1+\frac{\text { AnnualGrowthRate }}{100}\right)^{T}
$$

where $T$ is time interval between initial year and projected year. 


\subsection{Results and Discussions}

\subsection{LC distribution}

The LC maps and their area distributions together with percentage equivalent of the area of Zuru from 1988 to 2018 are presented in Figures 3a - 3d and 4. The results showed that the built-up cover (urban area) conspicuously increased with area of 693.35 ha (1.33\%), 728.74 ha (1.4\%), 5210.5 ha (9.98\%) and 6845.75 ha $(13.12 \%)$ respectively for the period of study (1988 to 2018). The increment in builtup area was indicative of population growth from 1988 to 2018 since the population estimates for the year 1988, 1998, 2008 and 2018 were computed as 97117, 130517, 175404, and 235728, respectively (see Table 4). It was also observed that rocky surface dwindled from 10,567.8 ha (20.25\%) in 1988 to $1985.84(3.81 \%)$ in 2018. This decrease could be attributed to either land conversion of the rocky surface into built-up area as a result of search for land for construction on a rocky foundation, or crushing of the rocky surface into granite of various sizes as building materials. The $9.98 \%$ area percentage of built-up in 2008 contradicted the $7.76 \%$ area percentage of built-up in 2008 of Bello et al. (2014). This disparity is due to difference in extent of study considered by both studies. This current study covered an area of $52,186.86$ ha $\left(521.868 \mathrm{~km}^{2}\right)$ while the former considered an area of $36.56 \mathrm{~km}^{2}$.

\section{Classification accuracy}

A confusion matrix was generated by comparing the value assigned during the classification process to the actual value from the satellite images. The matrix showed the user and producer accuracies, the errors of commission and omission, and the overall accuracy and the kappa coefficient. This is presented in Tables 2 and 3. The overall accuracies obtained for 1988, 1998, 2008 and 2018 were $88 \%, 86 \%, 86 \%$ and $64 \%$ respectively. There was $84 \%, 83 \%, 82 \%$ and $55 \%$ statistical agreement (kappa coefficient) between the reference points and the classified maps for 1988, 1998, 2008, 2018. This suggests that the supervised classification was done with the good refinement. However, the $64 \%$ and 55\% accuracy and kappa values for the LC map of 2018 was due to inevitable cloud cover and mixed-pixels in the image. Thus, it was moderately accurate, which is supported by Onsomgwong (2007) following Jensen (2005) stated that Landis and Koch (1977) concluded that Kappa values between $40 \%$ and $80 \%$ represent moderate agreement or accuracy. 
(a)



(c)

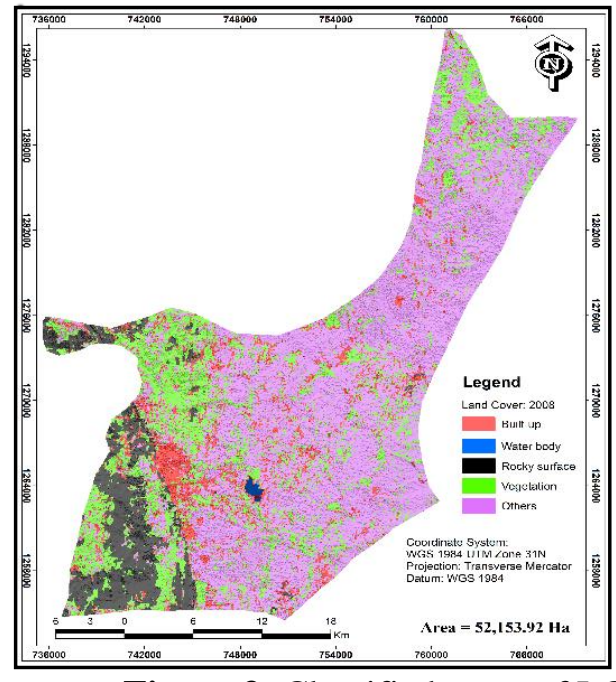

Figure 3: Classified maps of LC in Zuru (a) 1988 (b) 1998 (c) 2008 (d) 2018

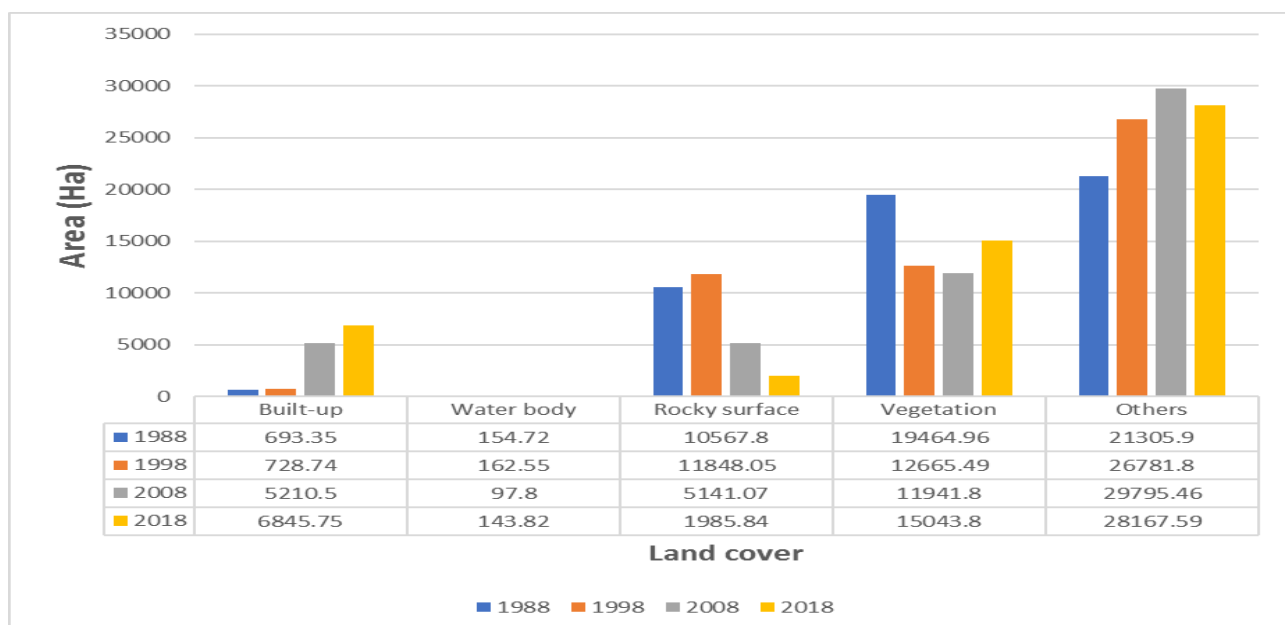

Figure 4: Land cover area for classified image maps of 1988, 1998, 2008 and 2018. (b)

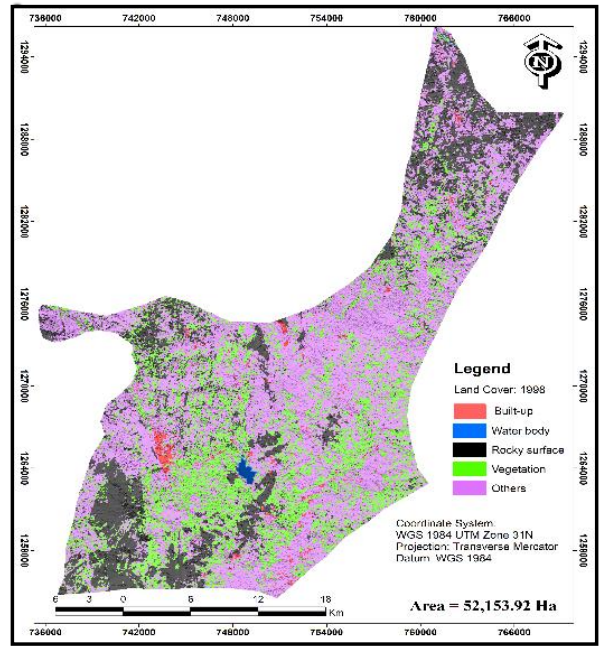

(d)

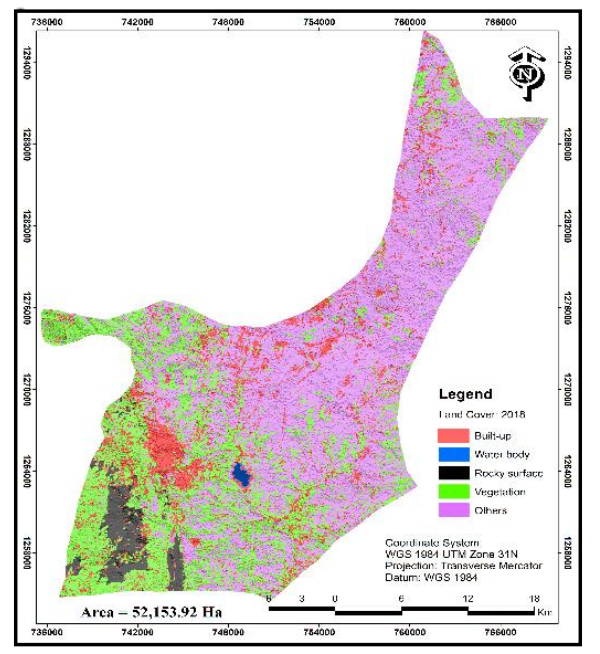


Table 2: Statistics for accuracy assessment of classified LC maps for 1988, 1998, 2008 and 2018

\begin{tabular}{|c|c|c|c|c|c|c|c|c|c|}
\hline \multirow[t]{2}{*}{$\mathrm{S} / \mathrm{N}$} & \multirow[t]{2}{*}{ Class } & \multicolumn{4}{|l|}{1988} & \multicolumn{4}{|l|}{1998} \\
\hline & & $\mathrm{A}_{1} \%$ & $\mathrm{~A}_{2} \%$ & $\overline{B_{1} \%}$ & $\mathrm{~B}_{2} \%$ & $\mathrm{~A}_{1} \%$ & $\mathrm{~A}_{2} \%$ & $\mathrm{~B}_{1} \%$ & $\mathrm{~B}_{2} \%$ \\
\hline 1 & Built-up & 5.88 & 34.69 & 94.12 & 65.31 & 12.20 & 28 & 87.80 & 72 \\
\hline 2 & Water body & 8.16 & 10.00 & 91.84 & 90.00 & 0 & 5.88 & 100 & 94.12 \\
\hline 3 & Rocky Surface & 17.24 & 4.00 & 82.76 & 96.00 & 22.22 & 2 & 77.78 & 98 \\
\hline 4 & Vegetation & 16.67 & 10.00 & 83.33 & 90.00 & 2.33 & 16 & 97.67 & 84. \\
\hline 5 & Others & 11.32 & 4.08 & 88.68 & 95.92 & 27.27 & 18.37 & 72.73 & 81.63 \\
\hline \multirow[t]{2}{*}{$\mathrm{S} / \mathrm{N}$} & Class & 2008 & & & & 2018 & & & \\
\hline & & $\mathrm{A}_{1} \%$ & $\mathrm{~A}_{2} \%$ & $\mathrm{~B}_{1} \%$ & $\mathrm{~B}_{2} \%$ & $\mathrm{~A}_{1} \%$ & $\mathrm{~A}_{2} \%$ & $\mathrm{~B}_{1} \%$ & $\mathrm{~B}_{2} \%$ \\
\hline 1 & Built-up & 33.33 & 18.37 & 66.67 & 81.63 & 57.81 & 35.71 & 42.19 & 79.59 \\
\hline 2 & Water body & 0 & 40 & 100 & 60 & 20.41 & 20.41 & 79.59 & 56 \\
\hline 3 & Rocky Surface & 0 & 8 & 100 & 92 & 24.32 & 44 & 75.68 & 40 \\
\hline 4 & Vegetation & 12.28 & 0 & 87.72 & 100 & 53.49 & 60 & 46.51 & 77.97 \\
\hline 5 & Others & 16.07 & 6 & 83.93 & 94 & 19.30 & 22.03 & 80.7 & 64.29 \\
\hline
\end{tabular}

Table 3: Overall accuracy and Kappa coefficient of Classified LC Maps for 1988, 1998, 2008 and 2018

\begin{tabular}{llll|}
\hline S/No & Year & Overall Accuracy (\%) & Kappa coefficient (\%) \\
1 & 1988 & 88 & 84 \\
2 & 1998 & 86 & 83 \\
3 & 2008 & 86 & 82 \\
4 & 2018 & 64 & 55 \\
\hline
\end{tabular}

\subsection{Urban growth detection}

Figure $5 \mathrm{a}-5 \mathrm{~d}$ presents the LC change between successive years. The bar to the right (green) signifies an increase while the bar to the left (red) signified a decrease. The land cover change metrics of Zuru from 1988 to 2018 is shown in Figure 5. It can be observed that the change in built-up area was 35.39 ha between 1988 and 1998, 4481.76 ha between 1988 and 2008, 1635.25 ha between 2008 and 2018, and 6152.41 ha between 1988 and 2018 respectively. This result signified an expansion in urban space of the study area. The built-up area class is the most important predictor of urban area expansion (Aliyu et al., 2020). Vegetation and rocky surface classes recorded losses in area change (see Figure $5 \mathrm{a}-5 \mathrm{~d}$ ) because they were converted and modified into built-up area. This is one of man-made influences on the biophysical cover as he expands his shelter. 
(a)

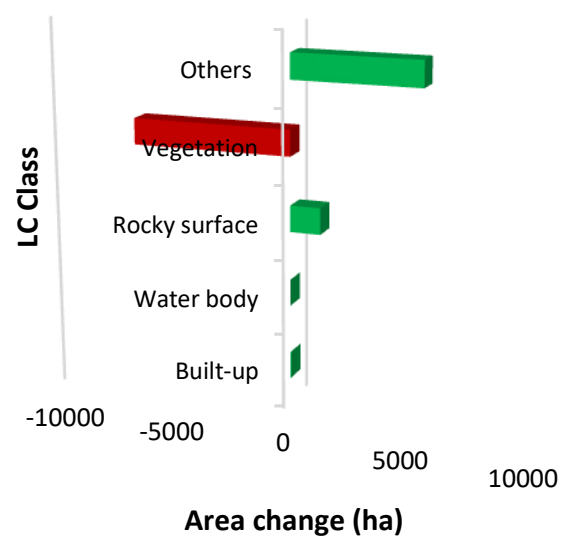

(c)

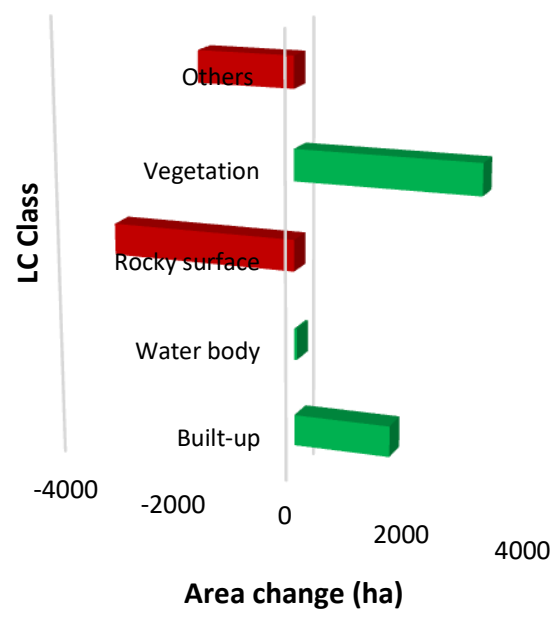

(b)

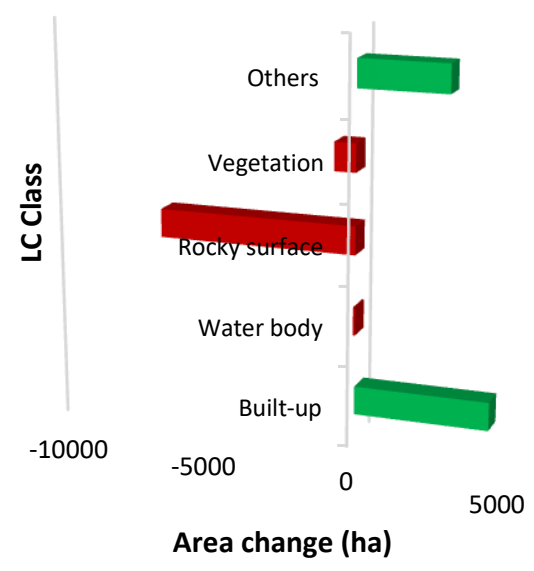

(d)

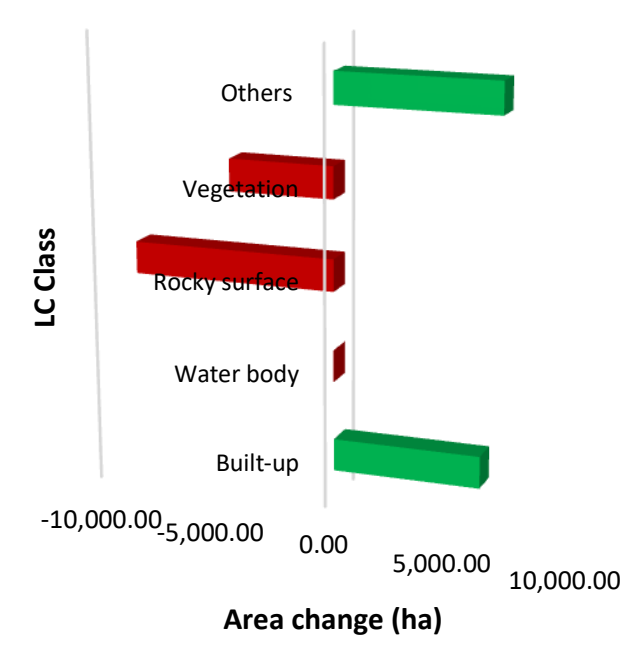

Figure 5: LC Area Change: (a) 1988-1998, (b) 1998-2008, (c) 2008-2018, and (d) 1988-2018.

\section{Land absorption coefficient/land consumption rate}

The projected population estimates for the year 1988, 1998, 2008 and 2018 were computed as 97117, 130517, 175404, and 235728, respectively (Table 4). The population figures were interpolated using a growth rate of $3 \%$ as reported by the National Population Commission (2010) and the baseline population of 2006 . The LCR decreased from $0.71 \%$ in 1988 to $0.56 \%$ in 1998 . It further increased from 1998 to $2.97 \%$ in 2008 and 2018 (see Table 4). This signified that there was crowdedness in urban area in 1988 compared to the year 1998. The increase in the LCR in 2008 and 2018 revealed that the crowdedness increased in the years 2008 and 2018 respectively. The pattern of LCR values of this study agreed with that of Laxmikant et al. (2012). The increase in LCR values from earlier to recent year of this study agreed with the works of Aliyu et al. (2020) and Oloukoi et al. (2014).

Furthermore, between 1988 and 1998, the LAC was 0.0011, it was 0.0998 between 1998 and 2008, and it was 0.0271 between 2008 and 2018 as shown in Table 4. This implied that between 1998-2008, new lands were explored for urban development and the population spread to the periphery than between 1988-1998 and 2008-2018. The LAC between 2008-2018 was also higher than between 1988-1998. The overall LAC between 1988-2018 was 0.0444, which was higher than the LAC (0.127) for a period of 1999-2019 for Akure, Ekiti state of Nigeria.as reported by Aliyu et al. (2020). Similarly, the LAC of this study was also higher than the LAC (0.013) for a period of 1986-2009 for Ile-Ife city, Osun state of Nigeria as reported by Oloukoi et al. (2014). 
Table 4: LCR/LAC of the urban area of the period of study

\begin{tabular}{llllllll}
\hline S/No & Year & Area (ha) & Population & LCR (\%) & Year & Area change & LAC \\
\hline 1 & 1988 & 693.35 & 97117 & 0.71 & $1988-1998$ & 35.39 & 0.0011 \\
2 & 1998 & 728.74 & 130517 & 0.56 & $1998-2008$ & 4481.76 & 0.0998 \\
3 & 2008 & 5210.5 & 175404 & 2.97 & $2008-2018$ & 1635.25 & 0.0271 \\
4 & 2018 & 6845.75 & 235728 & 2.90 & $1988-2018$ & $6,152.41$ & 0.0444 \\
\hline
\end{tabular}

\subsection{Conclusions}

This study evaluated the urban growth of Zuru LGA of Kebbi state, Nigeria in space and time. The datasets used for the evaluation were acquired for three decades (1988-2018). The LC distribution was determined for the established objectives. The study revealed that built-up (urban) area increased based on the percentage equivalent of area of $1.33 \%, 1.4 \%, 9.98 \%$ and $13.12 \%$ for the 1988,1998 , 2008 and 2018 respectively. This increment was detrimental majorly to the vegetation cover. From the findings, it revealed that Zuru is characterized by rock-outcrop, which was modified to urban area because of the reduction in size of the rock-outcrop being taken by the built-up area. The studied LULC results showed that the net change for the built-up area, waterbody, rocky surface, vegetation and others over the study period (1988-2018) to be $+6152.41 \mathrm{ha},-10.90 \mathrm{ha},-8582.05 \mathrm{ha},-4421.07 \mathrm{ha}$ and +40.82 ha respectively. The study established that the increment in urban area is commensurate to the rise in population growth. The LCR and LAC analyses revealed that there was crowdedness in the urban area in 2008 and 2018 as population increased. The LAC had it that between 1998-2008, new lands were sought for urban expansion. The findings of this study would serve as tool to decisionmakers in the management of land resources in the study area. It would also aid in visual communications during policy making. It was suggested based on the results of the study that the planning urban authority should develop urban planning measures by providing short-term and longterm planning since urban area has expanded and is distributed over the study area. This would ensure that vegetation and other covers are not converted and modified into urban area indiscriminately. Further studies should be conducted in the study area for periodic investigation of the urban growth.

Furthermore, it should be noted that socio-economic and climatic drivers of land cover to urban area were not accounted for in the study due to the unavailability of the datasets. However, the algorithms used for the study were within the acceptable results as compared to related studies.

\section{Conflict of Interest}

There is no conflict of interest among the authors.

\section{Acknowledgements}

The authors acknowledged the United States Geological Survey (USGS) for the provision of the datasets utilized for this study. Our utmost appreciation to the efforts of the anonymous reviewers that aided to improving the quality and readability of this report.

\section{References}

Abbas, I. I. and Iguisi, E. O. (2008). Building Remote Sensing Capabilities in Africa: The Nigerian Example. Proceedings of Map Africa 2008 Conference, Johannesburg, South Africa, August 21-22.

Abiodun, O. E., Olaleye, J. B., Dokai, A. N. and Odunaiya, A. K. (2011). Land Use Change Analyses in Lagos State From 1984 to 2005. FIG Working week, Bridging the Gap between Cultures, Marrakech, Morocco.

Aliyu, Y. A., Youngu, T. T., Abubakar, A. Z., Bala, A. and Jesulowo, C. I. (2020). Monitoring and Forecasting Spatio-Temporal LULC for Akure Rainforest Habitat in Nigeria. Reports on Geodesy and Geoinformatics, Sciendo. 110, pp. 29-38.

Anderson, J. R., Hardy, E. E., Roach, J. T. and Witmar, R. E. (1976). A Landuse/Land cover Classification System for use with Remote Sensor Data. Washington: United States Printing Office, Washington. 
Bakr, N., Weindorf, D. C., Bahnassy, M. H., Marei, S. M. and EI-Badawi, M. M. (2010). Monitoring Land Cover Changes in a Newly Reclaimed Area of Egypt using Multi-temporal Landsat Data, Applied Geography, 30(4), pp. 592-605.

Bhatta, B. (2010). Analysis of Urban Growth and Sprawl from Remote Sensing Data. Advances in Geographic Information Science. Springer. Springer Heidelberg Dordrecht London New York. DOI 10.1007/978-3-642-05299-6.

Bello, M. N., Idowu, I. A. and Benedine, A. (2014). Analysis of Land Use-Land Cover Changes in Zuru and Its Environment of Kebbi State, Nigeria Using Remote Sensing and Geographic Information System Technology. Journal of Geography and Earth Sciences, 2(1), pp. 113-126.

Fichera, C. R., Modica, G. and Pollino, M. (2012). Land Cover Classification and Change-Detection Analysis Uuing Multi-Temporal Remote Sensed Imagery and Landscape Metrics. European Journal of Remote Sensing, 45, pp. 1-18. doi: 10.5721/EuJRS20124501.

Forman, R. T. T. (1995). Some General Principles of Landscape and Regional Ecology. Landscape Ecology, 10(3), pp. $133-142$.

Foley, J. A., DeFries, R., Asner, G. P., Barford, C., Bonan, G. and Carpenter, S. R. (2005). Global Consequences of Land Use. Science, 309, pp. 570 - 574.

Ginblett, R. (2006). Modelling Human-Landscape Interactions in Spatially Complex Settings: Where are we and where are we going? MODISM05, pp. 11-20.

Jeevalakshmi, D., Reddy, S. N. and Manikiam, B. (2016). Land cover classification based on NDVI using LANDSAT8 time series: A case study Tirupati region. In: Procs. of International Conference on Communication and Signal Processing (ICCSP). doi:10.1109/iccsp.2016.7754369.

Jensen, J. R. (2005). Introductory Digital Image Processing: A Remote Sensing perspective. $3^{\text {rd }}$ Edition. Practice Hall.p526.

Landis, J. and Koch, G. (1977). The Measurement of Agreement for Categorical Data. Biometrics. Vol. 33: 159-174.

Land Satellites Data System (LSDS) (2019). Landsat 8 (L8) Data Users Handbook. LSDS-1574 Version 5.0: November, 2019. Retrieved from: https://prd-wret.s3.us-west2.amazonaws.com/assets/palladium/production/atoms/files/LSDS-1574_L8_Data_Users_Handbookv5.0.pdf. Downloaded on: 2 December, 2020.

Lambin, E. F., Rounsevell, M. D. A. and Geist, H. J. (2001). Are Agricultural Land-Use Models able to Predict Changes in Land Use Intensity? Agriculture, Ecosystems and Environment, 82.

Laxmikant, S., Pandey, P. C. and Nathawat, M. S. (2012). Assessment of Land Consumption Rate with Urban Dynamics Change using Geospatial Techniques. J. Land Use Sci. 7(2), pp. 135-148.

Mishra, V. N., Rai, P. K. and Mohan, K. (2014). Prediction of Land Use Changes based on Land Change Modeler (LCM) using Remote Sensing: A Case Study of Muzaffarpur (Bihar), India. $J$. Geogr. Inst. Cvijic. 64(1), pp. 111-127. DOI: 10.2298/IJGI1401111M.

Mmom, P. C. and Fred-Nwagu, F. W. (2013). Analysis of Land Use and Land Cover Change around the City of Port Harcourt, Nigeria. Global Advanced Research.

National Population Commission (NPC) (2006). National Population Commission: Nigerian Population Census Reports. Retrieved from: http://www.population.gov.ng. Downloaded on: 23 July, 2016. 
Ololade, O., Annegarn, H. J., Limpitlaw, D. and Kneen, M. A. (2008). Abstract of Land-Use/Cover Mapping and Change Detection in the Rustenburg Mining Region using Landsat Images, IGARSS 2008.

Oloukoi, J., Oyinloye, R. O. and Yadjemi, H. (2014). Geospatial Analysis of Urban Sprawl in Ile-Ife City, Nigeria. South African Journal of Geomatics, 3(2). DOI: http://dx.doi.org/10.4314/sajg.v3i2.2.

Ongsomwang, S. (2007). Fundamental of Remote Sensing and Digital Image Processing. School of Remote Sensing, Institute of Science, Suranaree University of Technology.

Oyinloye, M. A. (2010): Spatial Analysis of Urban Growth in Akure, Nigeria. [Doctorate Thesis Department of Urban and Regional Planning, Federal University of Technology, Akure]. Published.

Rimal, B., Sloan, S., Keshtkar, H., Sharma, R., Rijal, S. and Shrestha, U. B. (2020). Patterns of historical and future urban expansion in Nepal. Remote Sensing, 12(4), p. 628, doi:10.3390/rs12040628.

Singh, A. (1989). Review Article Digital Change Detection Techniques using Remotely- Sensed Data. International Journal of Remote Sensing, 10(6), pp. 989-1003.

Sundara Kumar, K., Sai Sankar Valasala, N. V. A., Subrahmanyam, J. V. V., Mallampati, M., Shaik, K. and Ekkirala, P. (2015). Prediction of future land use land cover changes of Vijayawada city using remote sensing and GIS. International Journal of Innovative Research in Advanced Engineering (IJIRAE), 2(3). Retrieved from: http://www.ijirae.com. Downloaded on: 29 November, 2018.

Susaki, J. and Shibasaki, R. (2000). Maximum Likelihood Method Modified in Estimating a Prior Probability and in Improving Misclassification Errors. International Archives of Photogrammetry and Remote Sensing, Vol. XXXIII, Part B7.

Tamilenthi, S. and Rajagopalan Baskaran, R. (2011). Detecting Urban Change of Salem City of Tamil Nadu, India from 1990 to 2010 Using Geospatial Technology. International Transaction Journal of Engineering, Management, \& Applied Sciences \& Technologies, 2(2). eISSN: 1906-9642. Available at http://TuEngr.com/V02/183-195.pdf.

United State Geological Survey (USGS). (2016). Landsat. Retrieved from: http://www.landsat.usgs.gov. Downloaded on: 10 April, 2019.

Viana, C. M., Oliveira, S., Oliveira, S. C. and Rocha, J. (2019). Land Use/Land Cover Change Detection and Urban Sprawl Analysis. Spatial Modeling in GIS and R for Earth and Environmental Sciences, pp. 621-651. doi:10.1016/b978-0-12-815226-3.

Wilson, I. D., Ware, J. M. and Ware, J. A. (2003). A genetic Algorithm Approach to Cartographic Map Generalization. Computers in Industry, 52(3), pp. 291-304.

Woldeamlak, B. (2002). Land Cover Dynamics since the 1950s in Chemoga Watershed, Blue Nile Basin, Ethiopia. Mountain Research and Development, 22, pp. 263-269.

Yikalo, H. A. (2009). Urban Land Use Change Analysis and Modeling: A case study of Setubal and Sesimbra, Portugal. [Master Thesis - University of Munster].

Yeates, M. and Garner, B. (1976). The North American City, Harper and Row Pub. New York.

\section{Cite this article as:}

Maleeks Y. A., Aliyu A. O., Bala A., Isiaka A. U. and Atta K. Z. 2021. Spatio-Temporal Evaluation of Urban Growth of Zuru Metropolis, Nigeria. Nigerian Journal of Environmental Sciences and Technology, 5(2), pp. 456-467. https://doi.org/10.36263/nijest.2021.02.0293 